Pacific Journal of Mathematic 


\section{A NOTE ON CERTAIN BIORTHOGONAL POLYNOMIALS}

\section{Carlitz}

Konhauser has introduced two polynomial sets $\left\{Y_{n}^{c}(x ; k)\right\}$, $\left\{Z_{n}^{\mathrm{c}}(x ; k)\right\}$ that are biorthogonal with respect to the weight function $e^{-x} x^{c}$ over the interval $(0, \infty)$. An explicit expression was obtained for $Z_{n}^{c}(x ; k)$ but not for $Y_{n}^{c}(x ; k)$. An explicit polynomial expression for $Y_{n}^{c}(x ; k)$ is given in the present paper.

1. Konhauser [2] has discussed two sets of polynomials $Y_{n}^{c}(x ; k)$, $Z_{n}^{c}(x ; k), n=0,1, \cdots, k=1,2,3, \cdots, c>-1 ; Y_{n}^{c}(x ; k)$ is a polynomial in $x$ while $Z_{n}^{c}(x ; k)$ is a polynomial in $x^{k}$. Moreover

$$
\int_{0}^{\infty} e^{-x} x^{c} Y_{n}^{c}(x ; k) x^{k i} d x= \begin{cases}0 & (0 \leqq i<n) \\ \neq 0 & (i=n)\end{cases}
$$

and

$$
\int_{0}^{\infty} e^{-x} x^{c} Z_{n}^{c}(x ; k) x^{i} d x= \begin{cases}0 & (0 \leqq i<n) \\ \neq 0 & (i=n) .\end{cases}
$$

For $k=1$, conditions (1) and (2) reduce to the orthogonality conditions satisfied by the Laguerre polynomials $L_{n}^{c}(x)$.

It follows from (1) and (2) that

$$
\int_{0}^{\infty} e^{-x} x^{c} Y_{i}^{c}(x ; k) Z_{j}^{c}(x ; k) d x= \begin{cases}0 & (i \neq j) \\ \neq 0 & (i=j) .\end{cases}
$$

The polynomial sets $\left\{Y_{n}^{e}(x ; k)\right\},\left\{Z_{n}^{c}(x ; k)\right\}$ are accordingly said to be biorthogonal with respect to the weight function $e^{-x} x^{c}$ over the interval $(0, \infty)$.

Konhauser showed that

$$
Z_{n}^{c}(x ; k)=\frac{\Gamma(k n+c+1)}{n !} \sum_{j=0}^{n}(-1)^{j}\left(\begin{array}{c}
n \\
j
\end{array}\right) \frac{x^{k j}}{\Gamma(k j+c+1)}
$$

As for $Y_{n}^{c}(x ; k)$, he showed that

$$
\begin{aligned}
Y_{n}^{c}(x ; k) & =\frac{k}{2 i} \int_{C} \frac{e^{-x t}(t+1)^{c+k n}}{\left[(t+1)^{k}-1\right]^{n+1}} d t \\
& =\frac{k}{n !} \frac{\partial^{n}}{\partial t^{n}}\left\{\frac{e^{-x t}(t+1)^{c+k n} t^{n+1}}{\left[(t+1)^{k+1}-1\right]^{n+1}}\right\}_{t=0} .
\end{aligned}
$$

In the integral in (5), $C$ may be taken as a small circle about the origin in the $t$-plane. 
In the present note we give a generating function and an explicit polynomial expression for the polynomial $Y_{n}^{c}(x ; k)$. Moreover we show that $Y_{n}^{c}(x ; k)$ can be identified with a polynomial studied recently by S. K. Chatterjea [1].

2. We apply the Lagrange expansion in the form $[4$, p. 125]

$$
\frac{f(t)}{1-w \phi^{\prime}(t)}=\sum_{n=0}^{\infty} \frac{w^{n}}{n !}\left\{\frac{d^{n}}{d t^{n}}\left[f(t)(\phi(t))^{n}\right]\right\}_{t=0},
$$

where

$$
w=\frac{t}{\phi(t)}, \quad \phi(t)=a_{0}+a_{1} t+\cdots \quad\left(a_{0} \neq 0\right) .
$$

Take

$$
f(t)=\frac{e^{-x t}(t+1)^{c} t}{(t+1)^{k}-1}, \quad \phi(t)=\frac{(t+1)^{k} t}{(t+1)^{k}-1} .
$$

Then we have

$$
1-w \phi^{\prime}(t)=\frac{k t}{(t+1)(t+1)^{k}-1},
$$

so that

$$
\frac{f(t)}{1-w \phi^{\prime}(t)}=e^{-x t}(t+1)^{c+1} .
$$

Thus, by (5) and (6), we have

$$
e^{-x t}(t+1)^{c+1}=\sum_{n=0}^{\infty} Y_{n}^{c}(x ; k)\left(\frac{t}{\phi(t)}\right)^{n}
$$

If we put

$$
w=\frac{t}{\phi(t)}=\frac{(t+1)^{k}-1}{(t+1)^{k}}=1-(t+1)^{-k},
$$

then

$$
t=(1-w)^{-1 / k}-1
$$

and (7) becomes

(8) $\quad(1-w)^{-(c+1) / k} \exp \left\{-x\left[(1-w)^{-1 / k}-1\right]\right\}=\sum_{n=0}^{\infty} Y_{n}^{c}(x ; k) w^{n}$.

In the next place, we have 


$$
\begin{aligned}
(1-w)^{-(c+1) / k} \exp \left\{-x\left[(1-w)^{-1 / k}-1\right]\right\} \\
=(1-w)^{-(c+1) / k} \sum_{r=0}^{\infty} \frac{x^{r}}{r !}\left[(1-w)^{-1 / k}-1\right]^{r} \\
=\sum_{r=0}^{\infty} \frac{x^{r}}{r !} \sum_{s=0}^{r}(-1)^{s}\left(\begin{array}{c}
r \\
s
\end{array}\right)(1-w)^{-(s+c+1) / k} \\
=\sum_{r=0}^{\infty} \frac{x^{r}}{r !} \sum_{s=0}^{r}(-1)^{s}\left(\begin{array}{c}
r \\
s
\end{array}\right) \sum_{n=0}^{\infty} \frac{((s+c+1) / k)_{n}}{n !} w^{n} \\
=\sum_{n=0}^{\infty} \frac{w^{n}}{n !} \sum_{r=0}^{n} \frac{x^{r}}{r !} \sum_{s=0}^{r}(-1)^{s}\left(\begin{array}{l}
r \\
s
\end{array}\right)\left(\frac{s+c+1}{k}\right)_{n},
\end{aligned}
$$

where

$$
(a)_{n}=a(a+1) \cdots(a+n-1), \quad(a)_{0}=1 .
$$

It therefore follows from (8) that

$$
Y_{n}^{c}(x ; k)=\frac{1}{n !} \sum_{r=0}^{n} \frac{x^{r}}{r !} \sum_{s=0}^{r}(-1)^{s}\left(\begin{array}{l}
r \\
s
\end{array}\right)\left(\frac{s+c+1}{k}\right)_{n} .
$$

3. Chatterjea [1] has defined the polynomial

$$
T_{k n}^{(\alpha)}(x)-\frac{1}{n !} x^{-\alpha} e^{x^{k}} D^{n}\left(e^{\alpha+n} e^{-x^{k}}\right)
$$

with $k=1,2,3, \cdots$. The case $\alpha=0$ had been discussed by Palas [3]. Chatterjea showed that (10) implies

$$
T_{k, n}^{(\alpha)}(x)=\sum_{r=0}^{\infty} \frac{x^{k r}}{r !} \sum_{s=0}^{r}(-1)^{s}\left(\begin{array}{c}
r \\
s
\end{array}\right)\left(\begin{array}{c}
\alpha+n+k s \\
n
\end{array}\right) .
$$

He also obtained operational formulas and a generating function for $T_{k, n}^{(\alpha)}(x)$. The assumption that $k$ is a positive integer is not used in deriving (11).

If we replace $k$ by $k^{-1}$ and $\alpha$ by $k^{-1} \alpha$, (10) becomes

$$
T_{k-1, k}^{(-1 \alpha)}(x)=\sum_{r=0}^{n} \frac{x^{k r}}{r !} \sum_{s=0}^{r}(-1)^{s}\left(\begin{array}{c}
r \\
s
\end{array}\right)\left(\begin{array}{c}
k^{-1}(\alpha+s)+n \\
n
\end{array}\right) .
$$

On the other hand, since

$$
\frac{1}{n !}\left(\frac{s+c+1}{k}\right)_{n}=\left(\begin{array}{c}
k^{-1}(s+c+1)+n-1 \\
n
\end{array}\right),
$$

(9) gives

$$
Y_{n}^{c+k-1}\left(x^{k} ; k\right)=\sum_{r=0}^{n} \frac{x^{k r}}{r !} \sum_{s=0}^{r}(-1)^{s}\left(\begin{array}{c}
r \\
s
\end{array}\right)\left(\begin{array}{c}
k^{-1}(s+c)+n \\
n
\end{array}\right) .
$$

It follows at once that

$$
Y_{n}^{c+k-1}\left(x^{k} ; k\right)=T_{k-1}^{(k-1} \cdot n(x),
$$


or, if we prefer,

$$
Y_{n}^{k \alpha+k-1}\left(x^{k} ; k\right)=T_{k^{-1, n}}^{(\alpha-1)}(x)
$$

4. It may be of interest to point out that a formula equivalent to (9) can be obtained without the use of the Lagrange expansion. In the integral representation (5), put

$$
t=(1+u)^{1 / k}-1 \text {. }
$$

Then (5) becomes

$$
Y_{n}^{c}(x ; k)=\frac{1}{2 \pi i} \int_{C} \frac{\exp \left\{-x\left[(1-u)^{1 / k}-1\right]\right\}(1+u)^{k^{-1}}(c+1)+n-1}{u^{n+1}} d u,
$$

where $C$ denotes a small circle about the origin in the $u$-plane. The numerator of the integral is equal to

$$
\begin{aligned}
\sum_{r=0}^{\infty} & \frac{x^{r}}{r !} \sum_{s=0}^{r}(-1)^{s}\left(\begin{array}{c}
r \\
s
\end{array}\right)(1+u)^{k^{-1}(c+s+1)+n-1} \\
& =\sum_{m=0}^{\infty} u^{m} \sum_{r=0}^{m} \frac{x^{r}}{r !} \sum_{s=0}^{r}(-1)^{r}\left(\begin{array}{c}
r \\
s
\end{array}\right)\left(\begin{array}{c}
k^{-1}(c+s+1)+n-1 \\
m
\end{array}\right) .
\end{aligned}
$$

Taking $m=n$, we therefore get

$$
Y_{n}^{c}(x ; k)=\sum_{r=0}^{n} \frac{x^{r}}{r !} \sum_{s=0}^{r}(-1)^{r}\left(\begin{array}{c}
r \\
s
\end{array}\right)\left(\begin{array}{c}
k^{-1}(c+s+1)+n-1 \\
n
\end{array}\right) .
$$

Since

$$
\left(\begin{array}{c}
c+n-1 \\
n
\end{array}\right)=\frac{(c)_{n}}{n !},
$$

it is evident that (14) is identical with (9).

5. Making use of the explicit formulas (4) and (9), we can give a rather brief proof of (3). Indeed we have

$$
\begin{aligned}
J_{n, m}= & \int_{0}^{\infty} e^{-x} x^{c} Z_{n}^{c}(x ; k) Y_{m}^{c}(x ; k) d x \\
= & \frac{\Gamma(k n+c+1)}{n !} \sum_{j=0}^{n}(-1)^{j}\left(\begin{array}{c}
n \\
j
\end{array}\right) \frac{1}{\Gamma(k j+c+1)} \\
& \cdot \frac{1}{m !} \sum_{r=0}^{m} \frac{1}{r !} \sum_{s=0}^{r}(-1)^{s}\left(\begin{array}{c}
r \\
s
\end{array}\right)\left(\frac{s+c+1}{k}\right)_{m} \cdot \int_{0}^{\infty} e^{-x} x^{k j+c+r} d x \\
= & \frac{\Gamma(k n+c+1)}{n ! m !} \sum_{j=0}^{n}(-1)^{j}\left(\begin{array}{c}
n \\
j
\end{array}\right) \\
& \cdot \sum_{r=0}^{m} \sum_{s=0}^{r}(-1)^{s}\left(\begin{array}{c}
r \\
s
\end{array}\right)\left(\frac{s+c+1}{k}\right)_{m}\left(\begin{array}{c}
k j+c+r \\
r
\end{array}\right) .
\end{aligned}
$$


If $f(x)$ is a polynomial of degree $m$, it is familiar that

$$
f(x)=\sum_{r=0}^{m}\left(\begin{array}{l}
x \\
r
\end{array}\right) \Delta^{r} f(0),
$$

where

$$
\Delta^{r} f(0)=\sum_{s=0}^{r}(-1)^{r-s}\left(\begin{array}{c}
r \\
s
\end{array}\right) f(s)
$$

In particular, for

$$
f(x)=\left(\frac{x+c+1}{k}\right)_{m}
$$

we have

$$
\begin{gathered}
\left(\frac{x+c+1}{k}\right)_{m}=\sum_{r=0}^{m}\left(\begin{array}{l}
x \\
r
\end{array}\right) \sum_{s=0}^{r}(-1)^{r-s}\left(\begin{array}{c}
r \\
s
\end{array}\right)\left(\frac{s+c+1}{k}\right)_{m} \\
=\sum_{r=0}^{m}\left(\begin{array}{c}
+x+r-1 \\
r
\end{array}\right) \sum_{s=r}^{n}(-1)^{s}\left(\begin{array}{c}
r \\
s
\end{array}\right)\left(\frac{s+c+1}{k}\right)_{m} .
\end{gathered}
$$

For $x=-k j-c-1$ this reduces to

$$
(-j)_{m}=\sum_{r=0}^{m}\left(\begin{array}{c}
k j+c+r \\
r
\end{array}\right) \sum_{s=0}^{r}(-1)^{s}\left(\begin{array}{c}
r \\
s
\end{array}\right)\left(\frac{s+c+1}{k}\right)_{m} .
$$

Thus

$$
\begin{aligned}
J_{n, m} & =\frac{\Gamma(k n+c+1)}{n !} \sum_{j=0}^{n}(-1)^{j}\left(\begin{array}{c}
n \\
j
\end{array}\right) \frac{(-j)_{m}}{m !} \\
& =(-1)^{m} \frac{\Gamma(k n+c+1)}{n !} \sum_{j=0}^{n}(-1)^{j}\left(\begin{array}{c}
n \\
j
\end{array}\right)\left(\begin{array}{c}
j \\
m
\end{array}\right) .
\end{aligned}
$$

Since

$$
\sum_{j=0}^{n}(-1)^{j}\left(\begin{array}{c}
n \\
j
\end{array}\right)\left(\begin{array}{c}
j \\
m
\end{array}\right)=\left(\begin{array}{c}
n \\
m
\end{array}\right) \sum_{j=m}^{n}(-1)^{j}\left(\begin{array}{c}
n-m \\
j-m
\end{array}\right)=(-1)^{m}\left(\begin{array}{c}
n \\
m
\end{array}\right)(1-1)^{n-m}
$$

it is evident that

$$
J_{n, m}=\frac{\Gamma(k n+c+1)}{n !} \delta_{n m}
$$

in agreement with (3). In particular

$$
J_{n, n}=\frac{\Gamma(k n+c+1)}{n !}
$$

as proved in [2].

A little more generally, we have 


$$
\begin{aligned}
J_{n, m}^{\prime} & =\int_{0}^{\infty} e^{-x} x_{c} Z_{n}^{c}(x ; k) Y_{n}^{c^{\prime}}(x ; k) d x \\
& =\frac{\Gamma(k n+c+1)}{n ! m !} \sum_{j=0}^{n}(-1)^{j}\left(\begin{array}{c}
n \\
j
\end{array}\right)\left(-j-\frac{c-c^{\prime}}{k}\right)_{m} \\
& =(-1)^{m} \frac{\Gamma(k n+c+1)}{n !} \sum_{j=0}^{n}(-1)^{j}\left(\begin{array}{c}
n \\
j
\end{array}\right)\left(\begin{array}{c}
j+a \\
m
\end{array}\right),
\end{aligned}
$$

where $a=\left(c-c^{\prime}\right) / k$. It follows that

$$
J_{n, m}^{\prime}= \begin{cases}0 & (n>m), \\
(-1)^{n+m} \frac{\Gamma(k n+c+1)}{n !}\left(\begin{array}{c}
a \\
m-n
\end{array}\right) & (n \leqq m) .\end{cases}
$$

Clearly (16) includes (15).

\section{REFERENCES}

1. S. K. Chatterjea, A generalization of Laguerre polynomials, Collectanea, Mathematica 15 (1963), 285-292.

2. J. D. E. Konhauser, Biorthogonal polynomials suggested by the Laguerre polynomials, Pacific J. Math. 21 (1967), 303-314.

3. F. J. Palas, A Rodrigues formula, Amer. Math. Monthly 66 (1959), 402-404.

4. G. Pólya and G. Szegö, Aufgaben und Lehrsatze aus der Analysis, Vol. 1, Berlin, 1925.

Received May 6, 1966. Supported in part by NSF Grant GP-5174. 


\section{PACIFIC JOURNAL OF MATHEMATICS}

\section{EDITORS}

\author{
H. ROYDEN \\ Stanford University \\ Stanford, California
}

\author{
J. P. JANS \\ University of Washington \\ Seattle, Washington 98105
}

J. DugundJI

Department of Mathematics

Rice University

Houston, Texas 77001

RICHARD ARENS

University of California

Los Angeles, California 90024

\section{ASSOCIATE EDITORS}
E. F. BECKENBACH
B. H. NeumanN
F. WOLF
K. YOSIDA

\section{SUPPORTING INSTITUTIONS}

\author{
UNIVERSITY OF BRITISH COLUMBIA \\ CALIFORNIA INSTITUTE OF TECHNOLOGY \\ UNIVERSITY OF CALIFORNIA \\ MONTANA STATE UNIVERSITY \\ UNIVERSITY OF NEVADA \\ NEW MEXICO STATE UNIVERSITY \\ OREGON STATE UNIVERSITY \\ UNIVERSITY OF OREGON \\ OSAKA UNIVERSITY \\ UNIVERSITY OF SOUTHERN CALIFORNIA
}

\author{
STANFORD UNIVERSITY \\ UNIVERSITY OF TOKYO \\ UNIVERSITY OF UTAH \\ WASHINGTON STATE UNIVERSITY \\ UNIVERSITY OF WASHINGTON \\ AMERICAN MATHEMATICAL SOCIETY \\ CHEVRON RESEARCH CORPORATION \\ TRW SYSTEMS \\ NAVAL ORDNANCE TEST STATION
}

\footnotetext{
Mathematical papers intended for publication in the Pacific Journal of Mathematics should be in typed form or offset-reproduced, double spaced with large margins. Underline Greek letters in red, German in green, and script in blue. The first paragraph or two must be capable of being used separately as a synopsis of the entire paper. It should not contain references to the bibliography. Manuscripts may be sent to any one of the four editors. All other communications to the editors should be addressed to the managing editor, Richard Arens, University of California, Los Angeles, California 90024.

Each author of each article receives 50 reprints free of charge; additional copies may be obtained at cost in multiples of 50 .

The Pacific Journal of Mathematics is published monthly. Effective with Volume 16 the price per volume (3 numbers) is $\$ 8.00$; single issues, $\$ 3.00$. Special price for current issues to individual faculty members of supporting institutions and to individual members of the American Mathematical Society: $\$ 4.00$ per volume; single issues $\$ 1.50$. Back numbers are available.

Subscriptions, orders for back numbers, and changes of address should be sent to Pacific Journal of Mathematics, 103 Highland Boulevard, Berkeley 8, California.

Printed at Kokusai Bunken Insatsusha (International Academic Printing Co., Ltd.), 7-17, Fujimi 2-chome, Chiyoda-ku, Tokyo, Japan.

PUBLISHED BY PACIFIC JOURNAL OF MATHEMATICS, A NON-PROFIT CORPORATION

The Supporting Institutions listed above contribute to the cost of publication of this Journal, but they are not owners of publishers and have no responsibility for its content or policies.
} 


\section{Pacific Journal of Mathematics}

\section{Vol. 24, No. $3 \quad$ July, 1968}

Duane W. Bailey, On symmetry in certain group algebras ............ 413

Lawrence Peter Belluce and Surender Kumar Jain, Prime rings with a one-sided ideal satisfying a polynomial identity ................ 421

L. Carlitz, A note on certain biorthogonal polynomials ............. 425

Charles O. Christenson and Richard Paul Osborne, Pointlike subsets of a manifold ......................................... 431

Russell James Egbert, Products and quotients of probabilistic metric

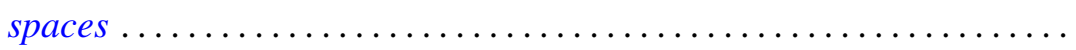

Moses Glasner, Richard Emanuel Katz and Mitsuru Nakai, Bisection into small annuli ..................................... 457

Karl Edwin Gustafson, A note on left multiplication of semigroup

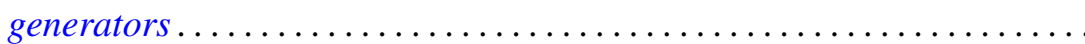

I. Martin (Irving) Isaacs and Donald Steven Passman, A characterization of groups in terms of the degrees of their characters. II ............. 467

Howard Wilson Lambert and Richard Benjamin Sher, Point-like

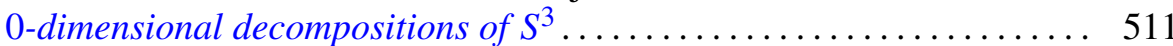

Oscar Tivis Nelson, Subdirect decompositions of lattices of width two ..... 519

Ralph Tyrrell Rockafellar, Integrals which are convex functionals . . . . . . . 525

James McLean Sloss, Reflection laws of systems of second order elliptic differential equations in two independent variables with constant coefficients ...

Bui An Ton, Nonlinear elliptic convolution equations of Wiener-Hopf type in a bounded region

Daniel Eliot Wulbert, Some complemented function spaces in $C(X)$

Zvi Ziegler, On the characterization of measures of the cone dual to a generalized convexity cone. 